\title{
Efficacy of Charcoal Toothbrush in Plaque and Stain Removal in Children Aged 10-14 Years
}

\author{
Sinjini Banerjee ${ }^{1}$, Anand Tavargeri ${ }^{2}$
}

\begin{abstract}
Introduction: From ancient times, powdered charcoal has been used as tooth-cleaning agent. Recent advance is the introduction of toothbrush with charcoal-infused bristles whose efficacy has not been scientifically well researched.

Aim and objective: The aim and objective of this article was to know the plaque and stain removal efficacy of charcoal toothbrush. Materials and methods: This single-blind, randomized clinical study was conducted on thirty 10-14-year-old schoolchildren. The plaque score using Quigley-Hein plaque index (modified) and stain score using Lobene index were assessed at baseline visit (prebrushing and postbrushing), after 30-day follow-up, and data collected were analyzed using paired $t$-test and independent $t$-test.

Results: No statistically significant difference was found for plaque removal efficacy between normal and charcoal toothbrush ( $p=0.749)$. Charcoal toothbrush (mean $=0.6554$ ) showed $28.82 \%$ better stain removal efficacy $(p=0.006)$ in comparison with normal toothbrush (mean $=0.1889$ ). Conclusion: Charcoal toothbrush has better stain removal efficacy in comparison with normal toothbrush.

Keywords: Charcoal toothbrush, Lobene, Plaque, Quigley-Hein index, Stain

Journal of Oral Health and Community Dentistry (2020): doi:10.5005/jp-journals-10062-0080
\end{abstract}

\section{INTRODUCTION}

From ancient times since the first use of charcoal by Hippocrates in Greece, powdered charcoal has been used as tooth-cleaning agent. Charcoal has been used in powder form, coal, soot ash having naturally porous formation, which helps to absorb bacteria and debris to effectively clean the teeth and gingiva. Recent advance is the introduction of toothbrush with charcoal-infused bristles, which was first introduced in Southeast Asian countries. The activated charcoal absorbs and binds bacteria to microscopic level and reduces halitosis compared to a conventional toothbrush. The activated charcoal in the bristles of the brush is proposed to absorb the tannins that bind to teeth and cause stains. There is no published data in literature about the efficacy of charcoal-infused toothbrush. The aim of our study was to know the plaque removal and stain removal efficacy of charcoal toothbrush.

\section{Materials and Methods}

This single-blind, randomized clinical pilot study was conducted on thirty 10-14-year-old schoolchildren. An informed consent was taken from the institutional review board, school authority, and parents. Thirty healthy schoolchildren were selected based on the inclusion criteria.

\section{Inclusion Criterion}

- Healthy schoolchildren aged between 10 years and 14 years with parents' consent.

\section{Exclusion Criterion}

- Children whose parents were not willing to participate,

- Children undergoing orthodontic treatment,

- Children with special healthcare needs and intellectually, physically challenged children,

\footnotetext{
${ }^{1,2}$ Department of Pediatric and Preventive Dentistry, SDM College of Dental Sciences and Hospital, Dharwad, Karnataka, India

Corresponding Author: Sinjini Banerjee, Department of Pediatric and Preventive Dentistry, SDM College of Dental Sciences and Hospital, Dharwad, Karnataka, India, Phone: +91 9681803693, e-mail: sinjini.khardah@gmail.com
}

How to cite this article: Banerjee S, Tavargeri A. Efficacy of Charcoal Toothbrush in Plaque and Stain Removal in Children Aged 10-14 Years. J Oral Health Comm Dent 2020;14(3):93-96.

Source of support: Nil

Conflict of interest: None

- Medically compromised children,

- Where permanent first molar and incisors have not erupted fully, and

- Children having more than four teeth having pit and fissure caries.

The plaque score using Turesky and Gilmore modification of Quigley-Hein plaque index using plaque disclosing agent (DPI AlphaPlac).

$0=$ no plaque,

1 = separate flecks or a discontinuous band of plaque at the gingival (cervical) margin,

2 = a thin (up to $1 \mathrm{~mm}$ ), continuous band of plaque at the gingival margin,

$3=\mathrm{a}$ band of plaque wider than $1 \mathrm{~mm}$ but less than $1 / 3$ of the surface,

$4=$ plaque covering $1 / 3$ or more, but less than $2 / 3$ of the surface,

$5=$ plaque covering $2 / 3$ or more of the surface.

Stain was scored using Lobene (1968) at baseline visit. 
The criteria and codes for intensity were:

$0=$ no stain present, natural tooth colorations,

$1=$ faint stain,

2 = clearly visible stain, orange to brown,

$3=$ dark stain, deep brown to black.

For the area/severity criteria, tooth surface was divided into two parts and scores were given.

$1=$ thin line, can be continuous,

$2=$ thick line or band,

$3=$ covering total area.

The area/severity criteria and codes for the body of the tooth were scored separately for buccal/labial and lingual/palatal surfaces.

Score for buccal/labial surfaces

$1=$ stain limit up to $1 / 3$ of area pits/grooves affected,

$2=$ stain outside pits and grooves, between $1 / 3$ and $2 / 3$ of areas, $10 \%$ of area affected,

$3=$ stain outside pits/grooves, more than $2 / 3$ of area affected than $10 \%$ of area affected.

Lingual/palatal code surfaces

$1=$ up to $1 / 3$ rd of the area affected,

$2=$ between $1 / 3$ rd and $2 / 3$ rd of areas affected,

$3=$ more than $2 / 3$ rd of area affected. ${ }^{2}$

Fifteen charcoal toothbrushes (Colgate slim soft charcoal toothbrush) and 15 normal toothbrushes (Colgate slim soft toothbrush) were randomly distributed among the sample after blinding the examiner. After brushing with the respective toothbrushes for 2 minutes with roll techniques, plaque and stain scores were noted. After 30 days of brushing, again plaque and stain index were observed. During follow-up period, one dropout was seen in normal toothbrush group. After data collection, the groups were disclosed, and then, the data collected were analyzed using paired $t$-test and independent $t$-test.

\section{Results And Observations}

Shapiro-Wilk test was done to know the normal distribution. $p>0.05$ was considered as statistically significant. Paired $t$-test for normal toothbrush showed 59\% reduction in plaque score from prebrushing at baseline to postbrushing $(p=0.000) .59 .25 \%$ reduction in plaque score was seen when compared between prebrushing at baseline and 30-day follow-up ( $p=0.000)$.

Paired $t$-test for charcoal toothbrush showed $50.8 \%$ reduction in plaque score from prebrushing at baseline to postbrushing $(p=0.001) .57 .1 \%$ reduction in plaque score was seen when compared between prebrushing at baseline and 30-day follow-up $(p=0.000)$.

When unpaired $t$-test was done to find the difference between normal toothbrush and charcoal toothbrush, the reduction in plaque score did not show any significant difference between the three types of brushes in prebrushing group $(p=0.556)$, postbrushing group ( $p=0.417)$, and follow-up group ( $p=0.749)$ (Table 1 and Fig. 1).

When paired $t$-test was done for stain assessment using the stain score with Lobene index, overall reduction in the stain score was seen in normal toothbrush group highest reduction of $54.8 \%$ seen in intensity $\times$ severity follow-up group compared to intensity $\times$ severity prebrushing group.

When paired $t$ test was done for stain assessment using the stain score with Lobene index, overall reduction in the stain
Table 1: Comparison between plaque removal efficacy of normal toothbrush and charcoal toothbrush

\begin{tabular}{|c|c|c|c|c|c|c|}
\hline & Group & $N$ & Mean & $\begin{array}{l}\text { Std. } \\
\text { deviation }\end{array}$ & $\begin{array}{l}\text { Std. error } \\
\text { mean }\end{array}$ & $p$-values \\
\hline \multirow{2}{*}{ Prebrushing } & Normal & 15 & 1.79 & 0.56317 & 0.14541 & 0.556 \\
\hline & Charcoal & 15 & 1.656 & 0.66557 & 0.17185 & \\
\hline \multirow{2}{*}{ Postbrushing } & Normal & 15 & 0.731 & 0.27451 & 0.07088 & 0.417 \\
\hline & Charcoal & 15 & 0.814 & 0.27534 & 0.07109 & \\
\hline \multirow{2}{*}{ Follow-up } & Normal & 14 & 0.744 & 0.26978 & 0.0721 & 0.749 \\
\hline & Charcoal & 15 & 0.71 & 0.28782 & 0.07432 & \\
\hline
\end{tabular}

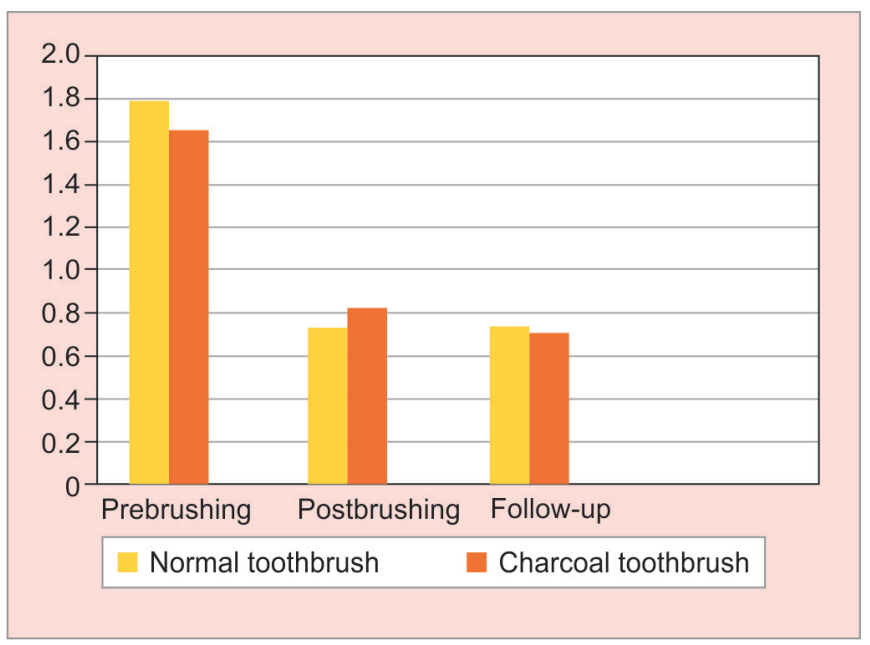

Fig. 1: Comparison between plaque removal efficacy of normal toothbrush and charcoal toothbrush

score was seen in charcoal toothbrush group. Highest reduction of $84 \%$ seen in intensity $\times$ severity follow up group compared to intensity $\times$ severity prebrushing group.

When unpaired $t$-test was done to compare between normal toothbrush and charcoal toothbrush, charcoal toothbrush showed better stain removal efficiency compared to normal toothbrush.

When stain score was compared using unpaired $t$-test between two toothbrush groups in gingival part of tooth, charcoal toothbrush showed $44.7 \%$ better stain removal efficiency compared to normal toothbrush group in postbrushing intensity $\times$ severity group ( $p=0.041) ; 38 \%$ better efficiency in intensity follow-up group ( $p=0.036$ ); and $58.4 \%$ better efficiency in follow-up severity group ( $p=0.007$ ). Highest stain removal was seen in follow-up intensity $\times$ severity group, and $75 \%$ better stain removal capacity of charcoal toothbrush was seen compared to normal toothbrush $(p=0.002)$ (Fig. 2).

When stain score was compared between two toothbrush groups using unpaired $t$-test in body part of tooth, charcoal toothbrush showed $51 \%$ better stain removal efficiency compared to normal toothbrush group in postbrushing severity group $(p=0.003) ; 55 \%$ better efficiency in postbrushing intensity $\times$ severity group ( $p=0.008$ ); and $75 \%$ better efficiency in follow-up severity group ( $p=0.001$ ). Highest stain removal was seen in follow-up intensity $\times$ severity group, and $82 \%$ better stain removal capacity of charcoal toothbrush was seen compared to normal toothbrush $(p=0.005)$ (Fig. 3). 


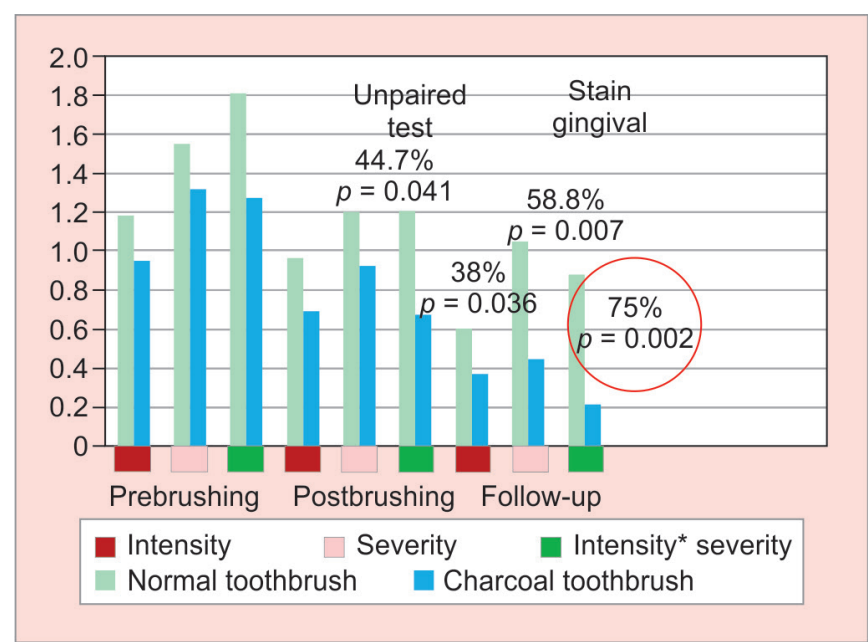

Fig. 2: Comparison between stain removal efficacy of normal toothbrush and charcoal toothbrush at gingival part of tooth

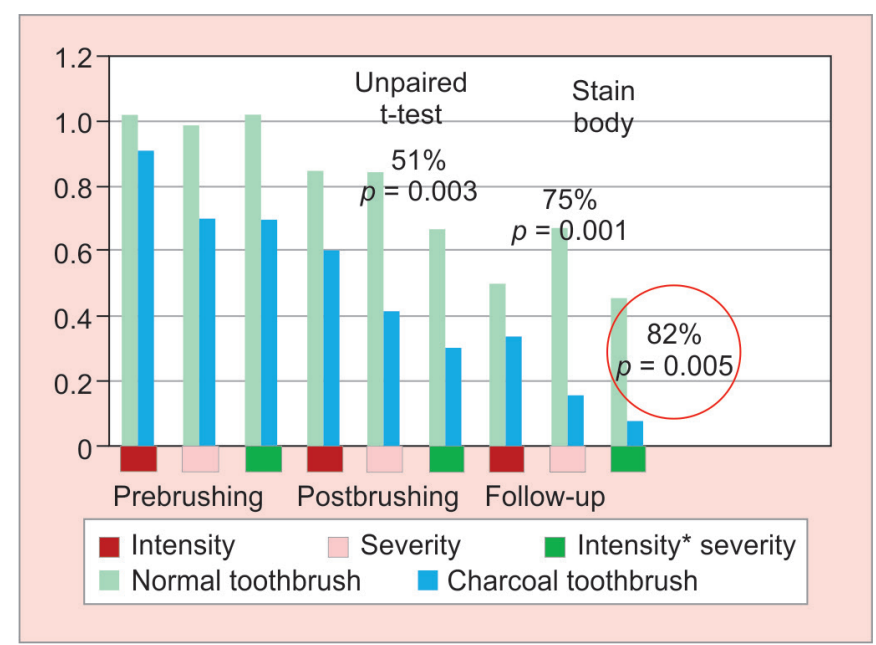

Fig. 3: Comparison between stain removal efficacy of normal toothbrush and charcoal toothbrush at body part of tooth

When stain score was compared between two toothbrush groups using unpaired $t$-test considering all sites of tooth charcoal toothbrush showed $38 \%$ better stain removal efficiency compared to normal toothbrush group in postbrushing severity group $(p=0.021) ; 46 \%$ better efficiency in postbrushing intensity $\times$ severity group ( $p=0.024)$; and $67 \%$ better efficiency in follow-up severity group ( $p=0.002$ ). Highest stain removal was seen in follow-up intensity $\times$ severity group, and $46 \%$ better stain removal capacity of charcoal toothbrush was seen compared to normal toothbrush $(p=0.006)$ (Fig. 4).

\section{Discussion}

Activated charcoal is the form of carbon, which is processed to incorporate small, low-volume pores to increase the surface area for adsorption, chemical reactions. The recent advancement is that

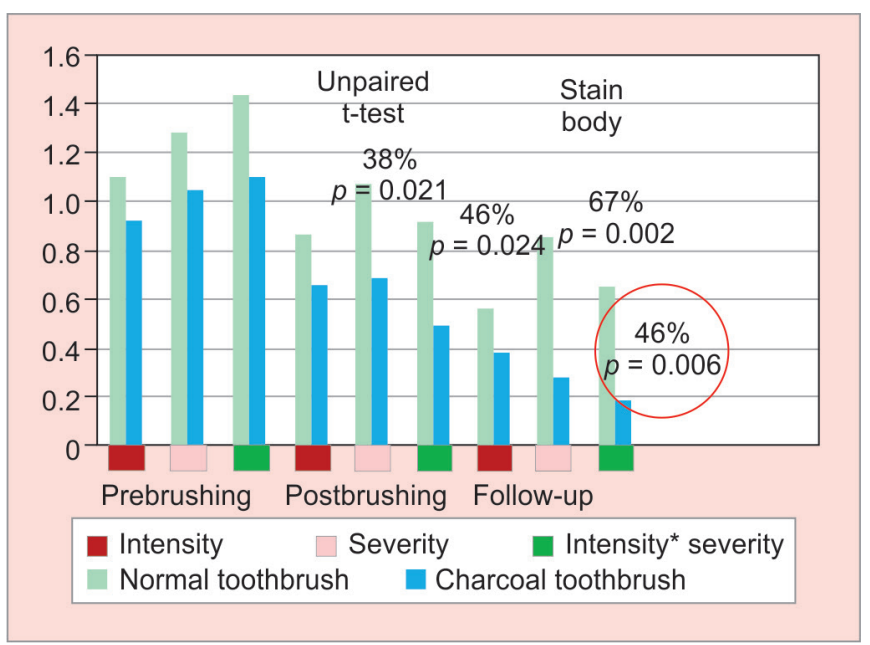

Fig. 4: Comparison between stain removal efficacy of normal toothbrush and charcoal toothbrush considering all sites of tooth

the charcoal infused the toothbrush bristles, which is claimed to absorb bacteria to microscopic level and reduce microbiological load in oral cavity. Our study is unique because there is no published literature found about charcoal toothbrush. The properties of activated charcoal explain the overall plaque reduction seen with the use of charcoal toothbrush. Activated charcoal absorbs the tannins that bind to teeth and cause stains. This explains the better stain removal efficiency of charcoal toothbrush compared to normal toothbrush found in our study. A study was done by Powell-Cullingford et al. in South India to compare between normal toothpaste, stick of neem tree, and charcoal in caries reduction efficacy in which charcoal showed $4 \%$ rate of caries, neem showed $10 \%$ incidence of caries, and normal toothpaste showed $100 \%$ incidence of caries. ${ }^{3}$ This may be correlated to the plaque reduction with charcoal toothbrush in our study because plaque is the etiological factor for caries. In contrast in a study done by Akhtar et al. in rural Bangladesh, higher incidence of caries was seen in children with cerebral palsy (71.4\%) who brushed with powder or charcoal as compared to normal toothpaste where caries incidence was $29.3 \% .{ }^{4}$ In a study done by Kalita et al. the efficacy of caries reduction was compared in 7233 children in Guwahati, India, in which lowest caries incidence was seen in chewing stick (8.5\%), followed by charcoal (38.7\%), toothbrush (41.8\%), and highest incidence was seen in finger rubbing (73.5\%). ${ }^{5}$

In a study done by Yaacob and Park (1990) in Tanah Merah District in Malaysia, it was observed that a subpopulation aged 35 to 55 years had the habit of cleaning teeth with charcoal, table salt applied with finger $(n=13)$ and melanoma stems as brush with no abrasive $(n=18) .{ }^{6}$ Charcoal showed the stain removal capacity but adverse effect of abrasion at labial surface of anterior teeth was seen due to long-standing use of charcoal powder.

On the contrary, in a study done by Majid et al. in Malaysia in 29,656 Children in 9,061 adults, it was seen that chewing sticks or charcoal or salt did not adversely affect the teeth surface. ${ }^{7}$ In our study after 1 month of follow-up, reduction in stain score was seen, which is due to the abrasive property of activated charcoal. In our study after follow-up period, charcoal did not adversely affect the tooth surface or dentin exposure was not noticed. 
Silver or gold nanoparticles are also infused in the bristles to enhance the antimicrobial efficacy. In a study done by Nascimento et al., the comparative analysis of antimicrobial efficacy of chlorhexidine-coated bristles, silver-infused bristles, and normal toothbrush was checked. After 1 month of follow-up, the silver-coated and chlorhexidine-coated bristles showed greater antimicrobial efficacy and maintained low levels of the bacterial counts of microorganisms like Tannerella forsythia, Treponema denticola, and Porphyromonas gingivalis, which is similar to the plaque reduction efficacy of charcoal-infused bristles. ${ }^{8}$ On the contrary, the study done by Al Ahmad et al. showed that the silver-coating did not reduce microbial count rather the colony counts of Streptococcus sanguis and Candida albicans were higher on silver-infused toothbrush bristles compared to the normal toothbrush. $^{9}$

\section{Conclusion}

Charcoal-infused toothbrush bristles have better stain removal efficacy compared to normal toothbrush. Plaque reduction was seen with the use of charcoal-infused toothbrush but when the plaque reduction potential was compared between normal and charcoal-infused toothbrush, no statistically significant difference was found. This pilot study can be used as a baseline for further research on charcoal-infused toothbrush with larger sample size and longer follow-up period.

\section{References}

1. Cugini M, Thompson M, Warren PR. Correlations between two plaque indices in assessment of toothbrush effectiveness. J Contemp Dent Pract 2006;7(5):1-9. DOI: 10.5005/jcdp-7-5-1.

2. Schäfer $F$, Huntington E. Comparison of a conventional, modified tooth stain index. J Clin Periodontol 2000;27(11):854-859. DOI: 10.1034/j.1600-051x.2000.027011854.x.

3. Powell-Cullingford HL. Charcoal controls caries; an account of a survey of the incidence of dental caries in southern India. Br Dent $J$ 1946;80(7):232-234.

4. Akhter R, Hassan NM, Martin EF, et al. Risk factors for dental caries among children with cerebral palsy in a low-resource setting. Dev Med Child Neurol 2017;59(5):538-543. DOI: 10.1111/dmcn.13359.

5. Kalita C, Choudhary B, Saikia AK, et al. Caries prevalence of schoolgoing boys and girls according to cleaning methods and soft drinktaking frequency in different localities, in and around Guwahati city. J Indian Soc Pedod Prev Dent 2016;34(3):249-256. DOI: 10.4103/09704388.186755.

6. Yaacob HB, Park AW. Dental abrasion pattern in a selected group of Malaysians. J Nihon Univ Sch Dent 1990;32(3):175-180. DOI: 10.2334/ josnusd1959.32.175.

7. Majid ZA. Dental health in Malaysia. Int Dent J 1984;34(4):261-265.

8. do Nascimento C, Paulo DF, Pita MS, et al. Microbial diversity of the supra- and subgingival biofilm of healthy individuals after brushing with chlorhexidine- or silver-coated toothbrush bristles. Can J Microbiol 2015;61(2):112-123. DOI: 10.1139/cjm-2014-0565.

9. Al-Ahmad A, Wiedmann-Al-Ahmad M, Deimling D, et al. An antimicrobial effect from silver-coated toothbrush heads. Am J Dent 2010 Oct;23(5):251-254. 